\title{
A frame-analytical perspective on conflict between people and an expanding wolf Canis lupus population in central Italy
}

Chiara Vitali

\begin{abstract}
Attempts to mitigate conflict between wolves and livestock breeding in the Mugello area of central Italy have so far proven to be costly, resource-intensive and fraught with tension. I applied frame analysis as a tool for investigating the roots of such tensions. The frameanalytical perspective highlighted that, while current policy focuses on improving technical approaches, conflict is also fuelled by a discrepancy in the frames of meaning that groups of stakeholders construct around the issue of wolf management. I outline two discordant frames: a dominant valuable wolf frame, currently underlying policy, and a political wolf frame that challenges existing management aims. Barriers to communication and potential points of mediation are identified. In addition, I outline a third, problematic wolf frame that may act as a potential aid in the process of bridging the two discordant frames, which is identified as a condition for successful wolf management.
\end{abstract}

Keywords Canis lupus, conservation policy, frame analysis, human dimensions, human-wildlife conflict, Italy, wolf

This paper contains supplementary material that can be found online at http://journals.cambridge.org

\section{Introduction}

Tuman-wildlife conflict is a threat to biodiversity 1 because threatened species are often involved (Knight, 2000; Woodroffe et al., 2005). This phenomenon is defined as 'relations of rivalry or antagonism between human beings and wild animals which typically arise from territorial proximity and involve reliance on the same resources or a threat to human well-being or safety' (Knight, 2000). In the case of carnivores in particular, wildlife managers have traditionally responded to this threat with direct instruments based on control, compensation and barriers (Genovesi, 2010). There is now, however, a growing interest in approaches focusing not only on direct mitigation but also on indirect mitigation targeting human dimensions, such as raising tolerance and addressing social factors

ChIARA Vitali* (Corresponding author) Keble College, University of Oxford, 23 Banbury Road, OX1 3PG, UK. E-mail crmvitali@gmail.com

${ }^{\star}$ Current address: 284 Hermitage Road, London, N4 1NR, UK

Received 10 July 2012. Revision requested 18 October 2012

Accepted 20 February 2013. First published online 14 May 2014. that may affect conflict situations (Bekoff, 2001; Bath \& Enck, 2003).

Developments in this field have interpreted some instances of human-wildlife conflict as surrogates for social tensions, for instance between groups of people or between people and the state (Knight, 2000; Nie, 2003). For successful mitigation this perspective implies an acknowledgement of the importance of understanding the political, cultural and social context in which interactions between people and wildlife take place.

Livestock depredation is one of the most prevalent causes of antagonism towards wildlife (Thirgood et al., 2005). The wolf Canis lupus has suffered from such antagonism to an extent that has threatened large sections of the global population (Boitani, 2003). Several of the species' characteristics, including its recovering status, high profile, nature as a large predator and prominent role in human imagination and folklore (Lopez, 1978; Kemmis, 2001) make it an apt subject of study for exploring the human dimensions of conflict with wildlife.

After falling to c. 100 individuals in the early 1970 s the Italian wolf population recovered following the introduction of a strictly protected status (which protects the wolf against deliberate killing, capture, disturbance and trading) under the Bern Convention (Bocedi \& Bracchi, 2004; Genovesi, 2010; for an overview of the wolf s legal status in Europe see Shine, 2005). Conflict mitigation in Italy is devolved to regional and local authorities, and thus there is variation in wolf management strategies. Monetary compensation for damage from wolf depredation is the most common measure, followed by the implementation of protective measures such as fencing and the use of guard dogs (Boitani, 2000; Genovesi, 2005). The sustained recovery of this wolf population has placed such direct conflict mitigation measures under strain; for example, many of the original direct compensation systems became financially burdensome. This created an opportunity for exploring the potential of indirect measures.

Research focusing on conflict between human activities and wolf populations in the Mugello area of central Italy has identified tensions between groups of stakeholders, underlying the human-wildlife conflict (Vitali, 2007; see also MacMillan, 1998). Here, I build upon previous work, applying frame analysis to data collected in interviews with stakeholders and policy makers involved in conflict with the wolf and its mitigation at the local, regional and national level. Applying frame analysis, a method that is 


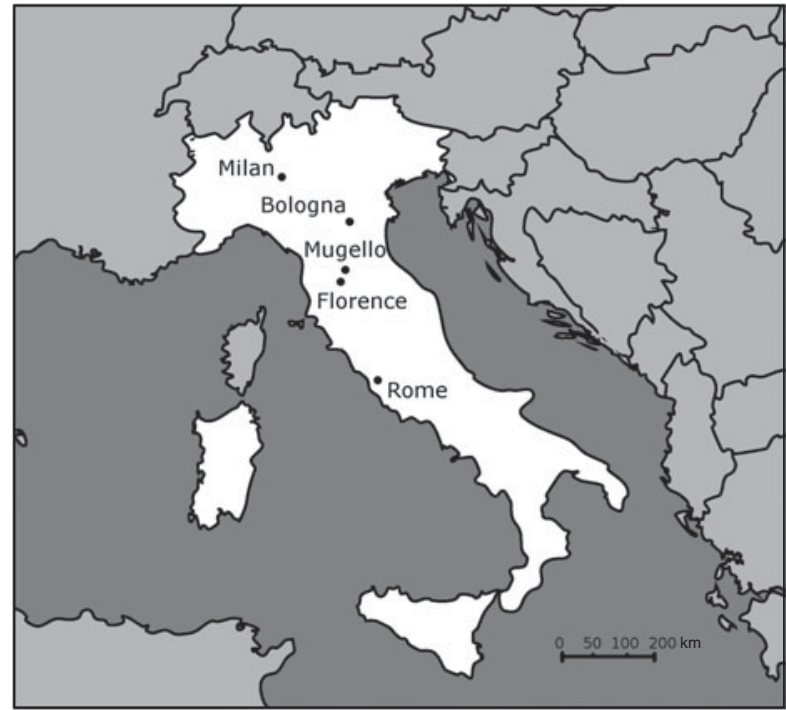

FIG. 1 The locations in Italy where interviews were conducted.

particularly appropriate for exploring tacit elements of discourse, facilitates an exploration of the deeper causes of the conflict. I suggest that underlying and magnifying human-wolf conflict are conflicting frames of meaning constructed around the species and a fundamental discrepancy in how groups of stakeholders approach its management. By exploring the underlying causes of this discrepancy, a frame-analytical approach may benefit wolf conservation efforts by identifying new opportunities for mediation between stakeholder groups and between stakeholders and policy-makers, facilitating better policy outcomes.

\section{Study area}

The Mugello is an area of c. 1,600 ha in northernmost Tuscany (Fig. 1). The landscape is a combination of woodland-covered hilly areas and more densely populated valleys, with a density of 65.9 people per $\mathrm{km}^{2}$ (ISTAT, 2001). Heavy depopulation during the 1960 s created a favourable environment for the return of the wolf, which had previously been eradicated from the area (Berzi, 1999). The local economy is primarily based on tourism and agriculture, with a strong presence of livestock farming specializing in local and rare breeds that are particularly vulnerable to wolf predation (Banti et al., 2005). Livestock holdings in the area in 2011 comprised 7,224 sheep and 11,182 cattle (Director, Associazione Regionale Allevatori Toscana, pers. comm.). In rural areas the tourism and farming industry often overlap as many farms also provide accommodation for holiday-makers and market produce to tourists.

Farmers and breeders, their representatives, members of the local administration and local researchers were recruited as respondents for this study. Respondents were also recruited in Florence (regional administrators), Rome (national-level administrators, technicians, researchers), Milan and Bologna (urban respondents).

\section{Methods}

Framing indicates the process by which individuals and groups 'attach meaning to events going on around them, ... fit their observations to their values and...relate that meaning to particular contexts of social behaviour or action' (Miller, 2000), with particular regard to complex situations, such as environmental debates (Benford \& Snow, 2000; Taylor, 2000; Wesselink \& Warner, 2010). Frames have been defined as the 'perceptual lenses' and underlying assumptions guiding individual and communal interpretations of an issue (Miller, 2000; Taylor, 2000). Frame analysis has been applied previously in environmental management and policy studies (Bardwell, 1991; Benford \& Snow, 2000; Creed et al., 2002) but not to the management of humanwildlife conflict.

With reference to environmental issues, frames guide interpretation, from the definition of a problem and attribution of responsibility to the identification of a solution, which are a frame's diagnostic and prognostic functions, respectively (initially identified in the context of social action frames; Miller, 2000, Taylor, 2000). This function of frames provides a means of engaging the array of arguments and counter arguments surrounding issues as complex as environmental policy (Creed et al., 2002). Frames may thus be conceptualized as lenses through which interactions between people and the environment are viewed. A number of elements help accentuate, define and communicate the frame: metaphors, exemplars, catchphrases, depictions, visual images, roots, consequences and appeals to principles (Schön \& Rein, 1994; Creed et al., 2002).

Central to this analysis is the concept of a policy frame (Schön \& Rein, 1994), defined as the 'structures of belief, perception, and appreciation' underlying policy positions (Kolkman et al., 2005). The often hidden nature of the frames that shape policy may exclude them from conscious attention and reasoning (Yanow, 1992; Schön \& Rein, 1994; Creed et al., 2002), even as the normative element embedded in these frames causes them to affect the policy outcome by setting priorities for policy-making (Wesselink \& Warner, 2010). By exploring such tacit frames and bringing them to the surface we hope to promote a more transparent and productive discussion of policy and management.

Also relevant to this study is the concept of frame alignment, originally defined as the linkage between interests, values and beliefs of the individual and the goals and ideology of a social movement (Snow et al., 1986). By extension to policy frames, alignment between the values underpinning policy and those held by stakeholders is 
viewed here as a condition for securing collaboration with policy measures.

The method chosen for data collection is shaped by awareness of the often tacit nature of policy frames. As some frames hold greater legitimacy than others, institutions may appear to sponsor one position in public utterances, while shaping their actions in accordance with a different frame (Schön \& Rein, 1994). I selected key informant interviews as a method that would go beyond the public domain, accessing tacit frames, and at the same time capture the 'complex and ambivalent ways in which people confront environmental issues and behaviours' (Kleese, 2002).

In this study I apply frame analysis to the results of 45 interviews, one formal and two informal group discussions, of 40-120 minutes in length. I conducted 23 interviews with policy-makers and administrators in June and July 2010. These were analysed alongside 22 interviews and three group discussions that I conducted during an attitudinal study in August and September 2006. The 2006 study consisted of interviews with stakeholders in human-wolf conflict, with particular focus on livestock breeders and environmentally engaged individuals from urban locations (Vitali, 2007). The three group discussions were carried out with environmentally engaged individuals (formal discussion), and livestock breeders (two informal discussions). During the design stage for the 2010 study I re-examined these data and found them appropriate for revisiting through frame analysis, thus acting as an initial basis for this study.

The 2006 interviews were conducted with the use of a discussion guide (Supplementary Material 1) that focused on attitudes towards the wolf and its conservation by exploring three main topics: attitudes to the wolf and its presence in Italy, wolf conservation and its impacts, and conflict with the wolf and mitigation measures. The discussion guide was designed as a flexible tool rather than as a structure for the interview. Respondents were allowed to lead the discussion and prompts were deployed only to ensure that all topics were discussed. In a number of interviews, particularly with rural dwellers, most topics were touched upon spontaneously with minimal need for prompting.

The aim when carrying out the interviews in 2010 was to collect data that would be sufficiently consistent with the data collected in 2006. Therefore, I chose to maintain as many of the original prompts as possible, compatibly with their appropriateness for an audience consisting of administrators, researchers and policy-makers (who could be expected to have a higher level of knowledge of the wolf), with the addition of a set of questions focusing on the policy-making process.

\section{Sampling frame}

Informants were selected using a sampling frame based on known elements of the debate surrounding wolf management. The policy instrument that compensates breeders who have suffered from wolf predation is a focal point of controversy (Boscagli et al., 2010). Therefore, I canvassed the views of those individuals responsible for designing and implementing this instrument in Tuscany. This involved consulting members of the regional administration responsible for designing the compensation scheme and employees of regional and local agencies responsible for its implementation $(\mathrm{n}=12)$.

In addition to the local stock breeders interviewed in $2006(n=12$, plus 2 informal groups of $n=4$ and $n=3)$ I consulted members of the local union of farmers and breeders, in 2010, as a means of reconnecting with the current context $(n=2)$. Environmentally engaged urbandwellers were also included in the 2006 sample $(n=10$ plus one formal group of $\mathrm{n}=8$ ). Urban-dwellers in Bologna were recruited from the membership of a non-profit organization, identified by a local contact, which had run ecotourism trips to the Mugello. Respondents were thus recruited as environmentally engaged individuals with an interest in the area of study. However, decisions concerning wolf management are made at the national level and the attitudes of people living in locations far removed from areas of wolf presence also influence policy. Therefore, I also recruited self-defining environmentally engaged individuals (defined by a declared interest in wildlife of the natural world, or current or past membership of environmental organizations, recorded in a preliminary telephone interview) in Milan through snowball sampling (Bernard, 1995) from personal contacts.

The protected status of the wolf is a second major point of contention. To explore this dimension I sought out informants operating at the national level who are responsible for defining the species' status in Italian territory and for setting the general guidelines for its management $(\mathrm{n}=9)$. This group included authors of the Wolf Recovery Action Plan (Genovesi, 2002) and collaborators recruited through snowball sampling, staff of the Ministry for the Environment, and the technical body that informs Ministry decisions, the Institute for Environmental Protection and Research.

\section{Analytical approach}

An iterative process was required, to make explicit and to isolate the underlying logic and assumptions that combine to shape individual policy frames. I began by identifying four salient themes, which were chosen to allow respondents' varying attributions of meaning to emerge most strongly. The themes were selected on the grounds that they emerged from the majority of interviews spontaneously and in connection with discourse indicating salience and high levels of conflict. In particular, mention of other stakeholder groups in connection with the theme was considered an 
indicator of conflict (for instance, when issues of power and representation emerged, farmers often spoke of the disproportionate power attributed to environmentalists). The four themes that emerged from this first iteration are:

The functioning of mitigation measures In Tuscany a system based on direct compensation was replaced in 2005 by subsidized insurance policies handled by a private company and conditional upon the implementation of preventive measures such as fencing. At the local level tension surrounds this change, which has caused public authorities to be perceived by local residents as retreating from their role in managing the wolf.

Issues of power and representation Debate over humanwildlife conflict has been known to generate a sense of rural communities under threat from both wildlife and its supporters (Nie, 2003; Skogen \& Krange, 2003), resulting in a discourse of disenfranchisement and distrust of public authority.

Legalized lethal control Italian policy aimed at the mitigation of conflict with the wolf is unusual in its complete avoidance of lethal control. Some have argued for its introduction to alleviate tension with farming activities and feelings of disempowerment amongst livestock breeders (Boitani, 2000; Bocedi \& Bracchi, 2004).

Illegal wolf killings An estimated $10-20 \%$ of the Italian wolf population is killed illegally each year, and this is the main cause of mortality of wild wolves in Italy (Viviani et al., 2006; Genovesi, 2010). The practice is viewed with equal strength by different groups as a necessary defence mechanism or a criminal act and hindrance to effective wolf management.

I then revisited the interview transcripts with a particular focus on the articulation of individual positions in connection with the four themes. The themes acted as focal points for focusing on the elements constituting each respondent's main framework: the definition of the issue, the allocation of responsibility and the delineation of further action (diagnostic and prognostic functions). This process was aided by identifying the accentuating and communicating elements of the frame, with particular focus on metaphors, exemplars, depictions and appeals to principles. Focusing on respondents' construction of meaning around the identified themes allowed the underlying logic and assumptions that combine to shape individual frames to be made explicit.

From this second iteration two categories of meaning construction emerged: the attribution of value to the wolf (linked to the diagnostic function of the frame), and the definition of conflict as a technical or justice issue (predominantly linked to the prognostic function). I identified the value attributed to the wolf and its conservation as ranging from little or negative value, to a significant positive intrinsic value. The framing of wolf management as a technical issue involves an assumption that management is pursuing appropriate goals, and identifies a need to improve existing policy tools as the source of most shortcomings of the system. The justice framing, on the other hand, implies that the objectives and principles behind current wolf management are inappropriate (in that they are perceived to be based on a flawed prioritization of wolf recovery over human activities) and require rethinking.

\section{Results}

Frames should not be considered as discrete entities but rather may overlap and influence each other. Furthermore, individuals may reshape their framing of an issue, sometimes radically, or simultaneously adopt elements of different frames (Callon, 1998). Because of the overlapping and overflowing nature of frames, all of the positions outlined here should not be read as starkly opposed but rather as points on a spectrum along which respondents situate themselves through their construction of meaning. In addition, the frames should not be considered as sharply defined categories but as conceptual groupings, within which individual positions may overlap or move over time.

\section{Policy frame 1: the valuable wolf}

The valuable wolf frame is dominant in terms of the number and political influence of its sponsors and its influence on legislation. It is shaped by the attribution of significant intrinsic positive value to the animal. This is reflected in respondents' definition of effective management, which is widely identified as promoting sustained population growth and expansion of the wolf's range. Conflict is deemed to be within acceptable limits in so far as it does not hinder this expansion. Wolf management is viewed as largely a technical issue. Current management objectives and approaches, such as compensation mechanisms, are considered broadly adequate as they have so far secured wolf population growth. Existing controversy and shortcomings of the system are attributed to the need to improve current policy instruments to pursue management objectives more effectively.

Although this frame is defined largely by the perspectives of administrators and policy-makers, the element of intrinsic value also applies to the urban public, granting the frame its resonance and influence over current management philosophy. This element of the frame, punctuated by metaphors and depictions of nature and wilderness, at times extends to the identification of the wolf as a powerful symbol of the natural environment (Mech, 1995; Naughton-Treves et al., 2003; Vitali, 2007), a process facilitated by the species' high profile.

In contrast with feelings of disenfranchisement expressed by many rural respondents, policy-makers argued 
that the difficulties faced by people locally were not disregarded, and expressed a willingness to create an approach that is fair and equitable:

We cannot manage the wolf in the Mugello as if it is there in isolation, human populations are there too ... We must find a middle ground, we cannot protect one or the other. (Regional administration employee)

On the one hand we have the pressure, motivation and duty, and also a legal obligation, to improve the wolf's conservation status. On the other hand, we cannot ignore the issues it causes in certain contexts, because we also have a duty to conserve certain agricultural and pastoral activities that hold great cultural, social and economic value. (Regional administrator)

The illegal killing of wolves is condemned in official policy documents and statements as a criminal act and as the main obstacle to successful recovery and management of the wolf. However, some sources argue that a lack of enforcement against illegal wolf killings (reflected by a non-existent history of prosecutions) is evidence of an informal policy approach of benign neglect towards the practice, characterized by prohibition in official discourse and tacit tolerance in reality (Boitani, 2000).

The avoidance of legalized lethal control displays a similar dichotomy. Lethal control is currently widely excluded from official debate. This position is viewed by some stakeholder groups as reflecting a taboo dictated by pressure on the part of environmentalist groups, favoured by the wolf s intrinsic value to the more numerous and politically influential urban population. However, this was also described unofficially by some policy-makers as a temporary measure that fits into an approach aimed at maintaining equilibrium and promoting sustainable growth of wolf populations, and that may be reconsidered provided the necessary conditions (starting from sufficient population recovery) are met.

\section{Policy frame 2: the political wolf}

The political wolf frame is confined largely to rural respondents but is remarkably cohesive and widespread amongst this group and its supporters. At its core lies a strong normative claim that human activities should be the first priority within any management strategy and, although wolf conservation and repopulation is broadly identified as a desirable outcome (at least theoretically and at a safe distance from human activity), little intrinsic worth is attributed to this goal.

Appeals to principle within this frame display points of commonality with environmental justice discourse (Taylor, 2000), such as the denunciation of the inequitable distribution of the burden of wolf conservation, which is perceived to benefit only the urban population who value the presence of the wolf as a sign of wilderness (McLaughlin et al., 2005), whereas its costs weigh primarily upon the rural population. Consistently, rhetoric typical of environmental justice discourse (Taylor, 2000) was deployed: of loss, primarily economic but also of one's work, of prioritizing animal welfare over that of humans, and of endangerment of local communities.

This element of political and justice framing contributes to a communication barrier between rural residents, policymakers and administrators. Although the latter propose technical solutions, such as funding for protective measures, informants at the local level openly chastise this approach, arguing that the management of the wolf is a purely political problem, neither technical nor practical, and cannot be solved by building fences' (Mountain community employee). The majority of rural respondents questioned the appropriateness of monetary compensation altogether, contrasting a rhetoric of loss, stewardship and workmanship to one of monetary value: 'It's not money that a good breeder, a good family man wants, it's the product [of his labour]' (Mountain community employee).

The perceived imbalance of political and economic power was a salient theme amongst rural respondents. There is a perception of belonging to a marginalized section of society unable to make its voice heard against more influential, vocal and organized lobbies, identified as consisting of urban residents and environmentalists: 'This animal has expanded and risks taking already marginal areas and marginalizing them even further' (Farmers' union representative).

The perceived outcome of this state of affairs is that unjust decisions are being made to satisfy the politically powerful urban majority, to the detriment of rural-dwelling minorities, and that, as a consequence, unreasonable demands are being imposed by categories of people who are unaware of the local context and its constraints.

Such issues of power and representation are inextricably linked with the declining state of the Italian agricultural sector, the financial difficulties faced by livestock breeders and the impression that under the new compensation system they are made to shoulder the burden of wolf conservation. The wolf's protected status, by generating a perceived relationship of ownership between the animal and the state, facilitates the creation of a conceptual link between the wolf and the daily struggles facing those who 'try and earn a living from this miserable earth' (Farmer).

Illegal killings of wolves are widely framed as a defence mechanism by livestock breeders. However, the perception of breeders is also that wolf killing is treated as a serious crime (a view that is consistent with the official position but not supported by data on prosecutions; Boitani, 2000): 'You kill a wolf, it's almost worse than if you'd killed a man' (Farmer).

The issue of lethal control is salient in this frame. Farmers and their associations tend to identify the influence 
of public opinion as the main obstacle to the implementation of this policy instrument, which is a further indicator of disenfranchisement and perceived marginalization.

\section{Policy frame 3: the problematic wolf}

The crucial characteristic of the problematic wolf frame is an assessment of the wolf's value based on its role within the ecosystem and its broader environment, including the human context. Although the wolf is valued, a notion is presented that its role should undergo constant reevaluation based on its ecological value and broader context, and management policies should be adjusted accordingly. Although this frame benefits from a limited number of sponsors (largely senior researchers and a limited number of administrators) these unique features potentially grant it great importance.

The introduction of an element of lethal control is advocated by many within this frame. Reluctance on the part of the authorities to apply this measure officially (and their apparent preference for benign neglect) is framed as a manifestation of a broader issue of lack of control and systematic management and an attempt to avoid difficult decisions, whilst at the same time essentially deceiving a large part of the public:

Faced with a difficult issue, one may choose to ignore it because the 'natural' running of the system might be politically more convenient and effortless. This is a solution that is not strategic or well thought out but that ends up pleasing most people. (Senior researcher)

Simultaneously, the influence exerted by the values of the general public in setting the boundaries of acceptable policy decisions is acknowledged, as is the limited political bargaining power held by the agricultural sector, and shortcomings on the part of institutions in setting up appropriate occasions for dialogue.

In summary, the problematic wolf frame views the current objectives of wolf management as broadly appropriate but highlights the shortcomings of current policy approaches. It also challenges their underlying logic, such as the attribution of intrinsic positive value to the wolf. These characteristics facilitate some crucial overlap with the other two frames.

\section{Discussion}

Interviews highlighted a problematic level of ambiguity and misunderstanding between groups over the aims of policy regarding wolf management. Such conflicting framings hinder effective implementation of management approaches and further a process of mutual stereotyping between farmers and policy-makers, obstructing communication. In particular, amongst environmentally engaged individuals the adoption of increasingly adversarial discourse by those seeking to affirm their position within the group may promote such stereotyping trends and raise barriers to compromise between groups, as documented in other contexts of conflict over the presence of large carnivores (Brox, 2000). Such dynamics promote disenfranchisement of rural minorities by furthering the impression of a central power dominated by a conservationist rhetoric insensitive to their needs.

The majority of administrators displayed a strong awareness that conflict mitigation is the most effective way to preserve the wolf, and of the importance for this process of considering the interests of livestock breeders and farmers. However, until all concerned parties succeed in creating a common language and reaching a shared, accepted definition of appropriate wolf management, calls for public participation and for more inclusive and equitable policy are likely to remain in the realm of rhetoric (Hull et al., 2003). Some form of alignment between the conflicting underlying frames must be found (Snow et al., 1986; Schön \& Rein, 1994).

The framing of the wolf's value within the problematic wolf frame may provide an appropriate language for mediating between opposing positions held by the main stakeholder groups and for tempering processes that hinder communication and compromise. Although compatible with the strong positive meaning constructed around the wolf by urban majorities, this framework may also prove acceptable to rural stakeholders because of its assumption that the wolf's presence must be justified and the advocacy for an element of lethal control.

The position of researchers as recognized experts and their knowledge of the wolf as a biological entity have the potential to grant this group moral legitimacy (legitimacy based on normative approval; Suchman, 1995) as interlocutors for the educated urban population and environmentalists (Williams et al., 2002). A position as respected interlocutors for the urban public could potentially combine with a frequent field presence and an understanding of the wolf in the context of human activity to secure pragmatic legitimacy (legitimacy based on pragmatic considerations motivated by self-interest; Suchman, 1995) amongst rural dwellers. A relatively removed position from many of the social and political pressures, and the element of distrust faced by members of the public administration (Brox, 2000) may allow greater actual and perceived neutrality, consolidating a role for researchers in bridging the various frames.

The strong elements of mutual stereotyping and disenfranchisement encountered within the valuable and political framings of the wolf highlight a severe lack of communication, which is aggravated by the proliferation of informal and ambiguous policy approaches. This is exemplified, for instance, by the widely differing perceptions 
amongst stakeholder groups of the consequences of killing a wolf.

With regards to the compensation system, the shift from direct compensation to insurance policies and the restrictions placed on eligibility were largely perceived by farmers as arbitrary choices reflecting neglect of their needs and of the overall difficulties of their trade, which are compounded by the issue of wolf predation. This resentment may be partially alleviated by greater transparency concerning the motivations for policy decisions.

The perceptions of livestock breeders of indifference on the part of the authorities ultimately are not supported by the framing of administrators and researchers of the issue of wolf management. Informants within these categories view themselves as sympathetic towards farmers' needs and conditions but also engaged in attempting to strike a delicate balance between contrasting pressures. Targeted, transparent communication directed at all stakeholder groups may help address stereotyping and the entrenchment of current feelings of alienation.

The introduction of lethal control is widely framed by farmers and their unions as a necessary step but one which the authorities refuse to consider on account of pressure from a majority advocating total protection. Greater transparency regarding the process and motivations for the administration's actions in this regard could also ease tensions.

The case of the Tuscan compensation mechanism highlights the potential for an apparently technical change to inflame issues in unpredicted ways. The wolf's protected status implies, to some, ownership by the state, causing the animal to become entangled with notions of public authority and with resentment towards public institutions. The interaction between this association and the change in policy tools has affected livestock breeders' risk management decisions (OECD, 2003), causing them to refuse to stipulate an insurance policy: 'Many breeders refuse to get insured on principle - they ask why they should pay for an insurance policy because of an animal that is protected by the state' (Provincial administrator).

The wolf's position (linked by its protected status to attitudes towards the state and by its symbolic meanings to notions of nature, but also of justice and power) requires a comprehensive approach in evaluating policy instruments. In addition to the technical aspect of each mechanism, its interaction with all elements surrounding the wolf, and with the wolf's own behaviour, must be considered. The species' entanglement with the issues outlined above is particularly relevant to those considering the introduction of lethal control, an instrument that shows a potential to diminish or inflame conflict reaching far beyond its direct effects.

A frame-analytical perspective allowed me to build upon classic attitudinal studies, and on their more recent developments interpreting perceived human-wildlife conflict as a symbol and surrogate for human-human conflict. These approaches to understanding stakeholder attitudes towards and perceptions of wildlife are well suited to detect the existence of conflict and its immediate dynamics. In the context of framing functions, this translates to the detection and analysis of conflict between elements of the prognostic functions of contrasting frames, which typically manifests itself in the form of debates over the appropriateness of responses to the issue.

Employing frame analysis facilitated a further analytical step, delving into the deeper causes of entrenched conflict over wolf management. In other words, frame analysis highlighted a crucial discordance in the diagnostic functions of competing frames, meaning that the nature of the issue and the overall objectives and guiding principles of wolf management in Italy are being brought into question by farmers and breeders and their supporters.

Semi-structured interviews are a powerful tool for exploring the logic underlying existing policy approaches. In particular, the combination of frame analysis and semistructured interviews facilitated the process of discerning the problematic wolf frame from other, more widely sponsored and intensely vocal, frames by teasing out and focusing on elements of discourse that would normally remain tacit and undetected by other methods. This in turn created a new opportunity for mediating between the two main frames and tempering the dynamics observed to avoid further misunderstanding and conflict between the proponents of these frames.

Framing is a cross-cultural phenomenon and frame analysis has been applied successfully to a range of contexts and issues. There are limitations to generalizing the recommendations that emerge from this study, as the specific articulation of respondents' frames of meaning is heavily influenced by their cultural, historical, social and economic context. However, the method applied in this study is transferable and has the potential to identify opportunities for improving conservation outcomes in a variety of contexts, either by bringing to the fore previously ignored, underlying causes of conflict or by identifying potential routes for mediation between conflicting frames of meaning.

\section{Acknowledgements}

I am grateful to Professor Paul Jepson of the University of Oxford and Professor Luigi Boitani of the University of Rome for their invaluable support and advice throughout this study, and to Dr Duccio Berzi for his crucial help in the initial stages of research. For their comments and feedback I also thank Dr Paolo Ciucci of the Univeristy of Rome, Dr Piero Genovesi of the Institute for Environmental 
Protection and Research, Drs Marco Caporioni and Andrea Monaco of Regione Lazio, and Dr Eugenio Duprè of the Italian Ministry for the Environment and Territory.

\section{References}

Banti, P., Bartolozzi, L. \& Cavallini, P. (2005) La gestione del lupo in Toscana. Biologia e Conservazione della Fauna, 115, 98-101.

Bardwell, L. (1991) Problem-framing: a perspective on environmental problem-solving. Environmental Management, 15, 603-612.

BAth, A.J. \& ENCK, J.W. (2003) Wildlife-human interactions in national parks in Canada and the USA. United States National Park Service. Social Science Research Review, 4, 11-33.

Bekoff, M. (2001) Human-carnivore interactions: adopting proactive strategies for complex problems. In Carnivore Conservation (eds J.L. Gittleman, S.M. Funk, D. Macdonald \& R.K. Wayne), pp. 179-195. Cambridge University Press, Cambridge, UK.

Benford, R.D. \& SnOw, D.A. (2000) Framing processes and social movements: an overview and assessment. Annual Review of Sociology, 26, 611-639.

Bernard, H.R. (1995) Research Methods in Anthropology: Qualitative and Quantitative Approaches. Altamira Press, Lanham, USA.

BerZI, D. (1999) Il lupo (Canis lupus) nel complesso demaniale GiogoCasaglia. Relazione Finale per la Comunità Montana. Ischetus, Florence, Italy.

Bocedi, R. \& BRACCHI, P.G. (2004) Evoluzione demografica del lupo (Canis lupus) in Italia: cause storiche del declino e della ripresa, nuove problematiche indotte e possibili soluzioni. Annali della Facoltà di Medicina Veterinaria di Parma, 24, 403-415.

Boitani, L. (2000) Action plan for the conservation of the wolves (Canis lupus) in Europe. Convention on the conservation of wildlife and natural habitats (Bern Convention). Nature and Environment Series, $113,1-84$.

Boitani, L. (2003) Wolf conservation and recovery. In Wolves: Behavior, Ecology and Conservation (eds L.D. Mech \& L. Boitani), pp. 317-340. The University of Chicago Press, Chicago, USA, and London, UK.

Boscagli, G., Tribuzi, S., Adriani, S. \& Calò, C.M. (2010) Il rapporto lupo/zootecnia nel comprensorio della VII Comunità Montana 'Salto-Cicolano' (RI): Il punto di vista degli allevatori e le proposte per la coesistenza. In Atti del convegno 'Ricerca scientifica e strategie per la conservazione del lupo (Canis lupus) in Italia. Quaderni per la Conservazione della Natura 33 (eds R. Caniglia, E. Fabbri, C. Greco \& E. Randi), pp. 313-332. Ministero dell'Ambiente-ISPRA, Rome, Italy.

BROX, O. (2000) Schismogenesis in the wilderness: the reintroduction of predators in Norwegian forests. Ethnos, 65, 387-404.

Callon, M. (1998) An essay on framing and overflowing: economic externalities revisited by sociology. In The Laws of the Markets (ed. M. Callon), pp. 244-269. Blackwell Publishers, Oxford, UK.

Ciucci, P. \& Boita Ni, L. (2005) Wolf-livestock conflict in Italy: knowledge, research and conservation. Biologia e Conservazione della Fauna, 115, 26-51.

Creed, W.E.D., Langstraat, J.A. \& Scully, M.A. (2002) A picture of the frame: frame analysis as technique and as politics. Organizational Research Methods, 5, 34-55.

Genovesi, P. (2002) Piano d'Azione Nazionale per la Conservazione del Lupo (Canis lupus), Quaderni per la Conservazione della Natura, 13. Mininistero per l' Ambiente-Istituto Nazionale Fauna Selvatica, Rome, Italy. Http://www.minambiente.it/home_it/showitem.html? lang=\&item=/documenti/biblioteca/biblioteca_0149_a.html [accessed 13 July 2006].

Genovesi, P. (2005) Reduction of conflicts and policies for large carnivore conservation in Italy. Biologia e Conservazione della Fauna, 115, 21-25.

Genovesi, P. (2010) Il Piano d'Azione Nazionale per la Conservazione del Lupo (Canis lupus). In Atti del convegno 'Ricerca scientifica e strategie per la conservazione del lupo (Canis Lupus) in Italia. Quaderni per la Conservazione della Natura 33 (eds R. Caniglia, E. Fabbri, C. Greco \& E. Randi), pp. 11-18. Mininistero per l' Ambiente-ISPRA, Rome, Italy.

Hull, R.B., Richert, D., Seekamp, E., Robertson, D. \& BuyноғF, G.J. (2003) Understandings of environmental quality: ambiguities and values held by environmental professionals. Environmental Management, 31, 1-13.

ISTAT (Italian National Institute for Statistics) (2001) $14^{\circ}$ Censimento Generale della Popolazione e delle Abitazioni (14th National Census). Http://dawinci.istat.it/daWinci/jsp/dawinci.jsp? $\mathrm{q}=$ plo200010484200o [accessed 2 January 2013].

Kemmis, D. (2001) Wolves as bioregional sovereigns. In Wolves and Human Communities: Biology, Politics and Ethics (eds V.A. Sharpe, B. Norton \& S. Donnelley), pp. 9-12. Island Press, Washington, DC, USA.

KLEeSE, B. (2002) Contested natures: wolves in late modernity. Society and Natural Resources, 15, 313-326.

Knight, J. (2000) Introduction. In Natural Enemies: People-Wildlife Conflicts in Anthropological Perspective (ed. J. Knight), pp. 1-35. Routledge, London, UK.

Kolkman, M.J., KoK, M. \& van der Veen, A. (2005) Mental model mapping as a new tool to analyse the use of information in decisionmaking in integrated water management. Physics and Chemistry of the Earth, 30, 317-332.

Lopez, B. (1978) Of Wolves and Men. Scribner, New York, USA.

MacMillan, T. (1998) Attitudes towards wolf conservation in the district of Scansano (Grosseto). Atti del Museo di Storia Naturale della Maremma, 17, 109-128.

McLaughlin, G.P., Primm, S. \& Rutherford, M.B. (2005) Participatory projects for coexistence: rebuilding civil society. In Coexisting with Large Carnivores: Lessons from Greater Yellowstone (eds T.W. Clark, M.B. Rutherford \& D. Casey), pp. 177-210. Island Press, Washington, DC, USA.

$\mathrm{MECH}$, L.D. (1995) The challenge and opportunity of recovering wolf populations. Conservation Biology, 9, 270-278.

Miller, C.A. (2000) The dynamics of framing environmental values and policy: four models of societal processes. Environmental Values, 9, 211-233.

Naughton-Treves, L., Grossberg, R. \& Treves, A. (2003) Paying for tolerance of wolves. Conservation Biology, 17, 1500-1511.

Nie, M. (2003) Beyond Wolves: The Politics of Wolf Recovery and Management. University of Minnesota Press, Minneapolis, USA.

OECD (Organisation For Economic Co-operation and Development) (2003) A Comparative Analysis of the Role of Insurance in the Management of Environment-related Risks. OECD Publications, Paris, France.

SCHÖn, D.A. \& ReIn, M. (1994) Frame Reflection: Towards the Solution of Intractable Policy Controversies. Basic Books, New York, USA.

Shine, C. (2005) Legal Report on the Possible Need to Amend Appendix II of the Convention for the Wolf. Council of Europe, Strasbourg, France.

Skogen, K. \& Krange, O. (2003) A wolf at the gate: the anti-carnivore alliance and the symbolic construction of community. Sociologia Ruralis, 43, 309-325. 
Snow, D.A., Rochford, Jr, E.B., Worden, S.K. \& Benford, R.D. (1986) Frame alignment processes, micromobilization, and movement participation. American Sociological Review, $51,464-481$.

Suchman, M.C. (1995) Managing legitimacy: strategic and institutional approaches. Academy of Management Review, 20, 571-610.

TAYLOR, D.E. (2000) The rise of the environmental justice paradigm. Injustice framing and the social construction of environmental discourses. American Behavioral Scientist, $43,508-580$

Thirgood, S., Woodroffe, R. \& Rabinowitz, A. (2005) The impact of human-wildlife conflict on human lives and livelihoods. In People and Wildlife: Conflict or Co-existence? (eds R. Woodroffe, S. Thirgood \& A. Rabinowitz), pp. 13-26. Cambridge University Press, Cambridge, UK.

Vitali, C. (2007) A qualitative study of attitudes towards a recovering wolf population in central Italy. BSc thesis. University College London, London, UK.

Viviani, A., Gazzola, A. \& Scandura, M. (2006) Il lupo: un predatore sociale ed adattabile. In Il lupo in provincia di Arezzo (eds M. Appollonio \& L. Mattioli), pp. 29-43. Le Balze, Montepulciano, Italy.
Wesselink, A. \& Warner, J. (2010) Reframing floods: proposal and politics. Nature and Culture, 5, 1-14.

Williams, C., Ericsson, G. \& Heberlein, T.A. (2002) A quantitative summary of attitudes towards wolves and their reintroduction (1972-2000). Wildlife Society Bulletin, 30, 1-10.

Woodroffe, R., Thirgood, S. \& Rabinowitz, A. (2005) The impact of human-wildlife conflict on natural systems. In People and Wildlife: Conflict or Co-existence? (eds R. Woodroffe, S. Thirgood \& A. Rabinowitz), pp. 1-12. Cambridge University Press, Cambridge, UK.

YANOW, D. (1992) Silences in public policy discourse: organizational and policy myths. Journal of Public Administration Research and Theory, 2, 399-423.

\section{Biographical sketches}

Chiara Vitali's research interests lie in the human dimensions of wildlife conservation and in the application of qualitative methods to policy studies. She has carried out research on wolf conservation in Italy since 2005 and in 2011 collaborated as a consultant with WWFItalia and the University of Rome in a LIFE study of attitudes towards the management of wolf hybrids in Tuscany. Recently she has been studying forest resource management in rural Tanzania. 